\title{
JOSÉ PABLO VALIENTE (1749-1817)
}

Emma D. Vidal, José Pablo Valiente (1749-1817). Ilustración, reformas y realismo en España y América. Universitat Jaume I, Castellón de la Plana, 2019, 255 pp.

Recuperar el papel de José Pablo Valiente como uno de los funcionarios más fieles al absolutismo es el objetivo de Emma D. Vidal en el presente libro. El recorrido a lo largo de su etapa formativa hasta el final de su carrera en el Consejo de Indias parece mostrarnos las contradicciones de un político que osciló entre el reformismo ilustrado y el constitucionalismo. La experiencia adquirida durante sus estancias en los territorios de ultramar lo acercó a un reformismo matizado por su pragmatismo. Sin embargo, mantuvo intactas las ideas monárquicas y absolutistas de las que fue un fiel heredero y que defendió con firmeza durante su actuación en las Cortes de Cádiz.

Cuatro décadas de la vida de Valiente son analizadas en los nueve capítulos que conforman este libro, organizados cronológicamente. Cuenta, además, con un prólogo, agradecimientos e introducción. El primer capítulo ofrece una visión detallada de su proceso de formación, al tiempo que presenta los cambios y reformas educativas que estaban teniendo lugar en el ámbito universitario. También demuestra sus estrechos vínculos con el estamento eclesiástico de su región natal (Higuera la Real), que resultaron muy oportunos para demostrar su limpieza de sangre en las diferentes pruebas de nivel académico para las que se le exigió.

De esta etapa, la autora destaca entre otras tareas realizadas por Valiente, su desempeño como abogado de la Real Audiencia y como catedrático de la Universidad de Sevilla. La primera puede considerarse como la más determinante a la hora de valorar su actuación como funcionario ilustrado. En ella coincidió con una de las figuras más importantes de la Ilustración española, Gaspar Melchor de Jovellanos y Ramírez, quien desempeñaba el cargo de oidor de la Real Audiencia. Aunque lo que lo condujo a Madrid en 1778 fue su cometido como abogado en causas judiciales en las que estuvieron implicados diversos asentistas del Consejo de Guerra. Su actividad en el Real Consejo y como miembro del Ilustre Colegio de Abogados de Madrid le permitió relacionarse con importantes cargos del poder judicial. Su acertada actuación en los casos judiciales que representó atrajo la atención del Ministro José de Gálvez, quien terminó proponiéndolo para el empleo de oidor de la Audiencia de Guatemala. Nombramiento que recibió de Carlos 
III el 14 de julio de 1782. Toda una recompensa si tenemos en cuenta que con anterioridad había solicitado, sin éxito, un puesto en la Audiencia de Santa Fe.

La despedida de la Universidad de Sevilla y el nombramiento de oidor en la Audiencia de Guatemala cierran la primera etapa de formación de Valiente como funcionario en la península. El inicio de la carrera en ultramar marcará una nueva etapa más cercana al reformismo que Emma Vidal describe a partir del segundo capítulo. Es en este período en el que Valiente comienza un acercamiento a la realidad de las colonias y en el que se destacan los vínculos con su benefactor, José de Gálvez. Uno de los primeros encargos hechos por el Ministro de Indias fue el juicio de residencia del presidente saliente de la Audiencia, D. Matías de Gálvez, hermano del ministro.

La capacidad y eficiencia de Valiente, unido a los conocimientos adquiridos y al interés con que desempeñó su labor de oidor, le permitieron convertirse en asesor de la presidencia en los ramos del tabaco, de la pólvora y de los naipes entre 1783 y 1785. En esos años la Real Hacienda de Guatemala alcanzó saldos muy positivos. Sin embargo, fue su desempeño como superintendente de la Casa de la Moneda desde 1784 el que muestra la imagen más innovadora de Valiente. Especialmente el ensayo que realizó de una nueva aleación de la moneda de oro, lo que significó un importante ahorro para la Real Hacienda, así como el estricto control de pesos que ejerció durante todo el proceso. Gracias a su vigilancia conoció cada una de las etapas del proceso de producción y acuñación de las monedas y pudo determinar la fase en la que se perdía mayor cantidad de metal. Demostró un gran celo por el control de las cuentas al frente de la Casa de la Moneda, así como en los ramos de la pólvora, los naipes y el tabaco. Para evaluar el estado real de las mismas dispuso un sistema de cuentas separadas y de periodicidad anual.

En 1786 el fallo del juicio de residencia de Valiente reafirmó la capacidad e integridad que antes había llevado a Gálvez a proponerlo para la plaza de oidor de la Audiencia de Guatemala. Un juicio impoluto que confirmaba que su desempeño había sido «bueno, fiel y exacto ministro». Cualidades que fueron recompensadas con una plaza de fiscal en la Audiencia de México. La experiencia que logró acumular en asuntos relacionados con la justicia como abogado de la Audiencia de Sevilla, en Madrid y como oidor de la Audiencia de Guatemala, pero sobre todo, su fidelidad a la monarquía y la confianza que merecía a sus protectores en la Corte, determinaron que fuera elegido para hacer una investigación reservada fuera de la jurisdicción de la Audiencia de México. Se trataba de un fraude a la Hacienda Real en la isla de Cuba, ocurrido durante la guerra con Inglaterra entre 1779 y 1783 , que lo llevó a ocupar de forma interina la Intendencia de La Habana en los años 1787 y 1788. La forma en que fue designado para ocupar dicho cargo provocó críticas posteriores, especialmente por su cercanía a la familia Gálvez. También por su gestión, ya que sus críticos consideraban que tendió a favorecer a los comerciantes extranjeros y a no atender debidamente el abastecimiento en las zonas que dependían de la intendencia habanera. Para demostrar la importancia que alcanzó el comercio con los nacionales y lo desacertadas que resultaron las críticas realizadas a la gestión de Valiente la autora se apoya en el número de embarcaciones que entraron y salieron de la isla, hacia o desde otros puertos de América. Sin embargo, no especifica si 
estos se ubicaban en dominios españoles, ni tampoco los pabellones de los navíos contabilizados.

En cualquier caso, fueron importantes los problemas administrativos y la implicación de importantes cargos de la isla en el fraude a la Hacienda cubana que investigó Valiente. Cuatro años demoraron sus pesquisas, y gracias al celo con las que las realizó, la Real Hacienda recuperó un importante número de bienes y propiedades que fueron embargados a los implicados. La autora considera que el paso del funcionario por la intendencia no solo sirvió para demostrar que era capaz de arreglar las cuentas, sino también de controlar a los criollos.

Esto último es lo que Emma Vidal aborda en el cuarto capítulo al analizar el período de Valiente como intendente de Real Ejército y Hacienda en Cuba entre 1791-1799. Este período cierra el ciclo de formación que le permitió conseguir más tarde una plaza en el Consejo de Indias. Al mismo tiempo representa su etapa más reformista de cara a las colonias. Fallecidos su promotor, Gálvez, y el monarca Carlos III, su ascenso en la administración fue más lento, teniendo que esperar hasta 1794 para ocupar en propiedad la plaza de intendente de Real Ejército y Hacienda. De este período destaca la profunda reorganización que hizo de la Intendencia habanera, así como de la Junta del Real Consulado y Agricultura para el fomento de la esclavitud en la isla y la adopción de medidas comerciales opuestas al monopolio mercantil de la metrópoli. En concreto, su apoyo al capitán general Luis de las Casas en la decisión de mantener abierto el puerto habanero al comercio de neutrales en 1793. También su implicación en los proyectos de embellecimiento de La Habana y en la participación en la vida social habanera a través de sus instituciones. Por ejemplo, en la Sociedad Económica de Amigos del País de la que fue nombrado presidente honorífico en 1798 y desde la que estableció estrechas relaciones (también mercantiles) con Francisco de Arango y Parreño.

A partir del quinto capítulo y hasta el octavo, la autora nos ofrece un análisis de la actividad de Valiente en la península entre 1800 y 1813, concretamente en el Consejo de Indias y como diputado de las Cortes de Cádiz. Su desempeño como intendente de La Habana concluyó en 1799, año en que fue relevado del cargo y nombrado ministro togado supernumerario del Consejo de Indias. Aunque su llegada a la península tuvo lugar en 1800 a bordo de la goleta Delfín, no asumió el puesto en el Consejo hasta cuatro años más tarde, en junio de 1804. La causa del retraso se debió a que fue acusado, y condenado como responsable, de desatar la epidemia de fiebre amarilla a su llegada a Cádiz. Inconforme por el tratamiento recibido apeló a la Audiencia de Sevilla. Finalmente, la resolución de la Audiencia lo liberó de toda responsabilidad en la expansión de la epidemia, al tiempo que concluyó que el procedimiento que se le siguió había sido irregular y carente de pruebas sólidas. Probablemente, una demostración de que se había granjeado no pocos e importantes enemigos.

Superado el mal trance, Valiente se incorporó a las obligaciones del Consejo en la Sala de Justicia hasta que la conspiración del Escorial, los sucesos de Aranjuez y la marcha de la familia Real a Bayona le forzaron a abandonar Madrid. Aunque solicitó permiso para hacerlo alegando problemas de salud, la causa real tenía que ver con su sentido patriótico y su rechazo a José I. 
Disuelto el Consejo de España e Indias y conformada la Junta Suprema Central fue propuesto por Jovellanos junto a Manuel de Lardizábal, José Antonio Mon y Velarde, Antonio Ranz Romanillos y otros, para integrar la comisión que debía elaborar la convocatoria a Cortes y las líneas del futuro proyecto constitucional. Su cercanía con el pensamiento tradicionalista de Jovellanos se reflejaba en su defensa de que la convocatoria incluyera los estamentos eclesiástico, militar y civil, mientras que los liberales consideraban que debía convocarse sin distinción de estamentos y con separación de poderes. Sobre la cuestión de la administración en América defendía el regreso al sistema de gobierno de Gálvez. Es decir, un gobierno especial "porque las colonias eran distintas y distantes por lo que no podían ser igualadas”. Al mismo tiempo defendía la libertad de comercio, probablemente condicionado por su experiencia adquirida en la Intendencia de La Habana. En sentido general, puede decirse que esta etapa presenta al Valiente más absolutista, y defensor del modelo monárquico del despotismo ilustrado en el que se había formado. Su defensa del absolutismo le valió ser calificado de servil por la opinión pública de Cádiz. Fue, además, el único miembro de la Comisión que se negó a firmar el proyecto constitucional resultante.

Otra de las facetas que analiza Emma Vidal es la de diputado en las Cortes de Cádiz. Por un lado vemos la coherencia de Valiente, alejándose de quienes consideraban que era necesario realizar reformas profundas en las estructuras del Estado y acercándose a los que estaban más preocupados por asegurar la monarquía y la integridad del reino frente a los problemas americanos. Por otro, demostraba estar convencido de la necesidad de conceder representación política en las cortes extraordinarias a los habitantes de ultramar. Entre otras razones, porque evitaría el debilitamiento de los defensores de la monarquía en las colonias; especialmente, en momentos tan inestables como los que se vivían en la península con la ocupación francesa.

Su labor como diputado en Cortes terminó el 26 de octubre de 1811 de manera abrupta. Su salida de la sala del Congreso y el abandono definitivo de las Cortes se vieron forzadas por las continuas interrupciones por parte de los liberales mientras hacía uso de la palabra. Para la autora, reflejo de los desencuentros que desde hacía meses se venían produciendo entre el parlamentario líder «realista» y el liberal Agustín Argüelles. Concretamente, desde el mes de julio cuando Valiente se opuso a la pretensión de Argüelles, de trasladar el proyecto de Constitución a la Cámara para su aprobación. Valiente salió del Congreso sin que la institución pudiera garantizar su seguridad personal. Identificado por la opinión pública como contrario a la Constitución tuvo que abandonar Cádiz de inmediato. Fue su retirada definitiva de las Cortes.

Finalmente, en el capítulo nueve la autora nos muestra la última etapa del funcionario fiel y leal a la monarquía borbónica. Una fidelidad que fue reconocida nada más producirse la restauración absolutista en 1814. Ese año fue llamado a ocupar una plaza como ministro togado en el Consejo de Indias. Por su experiencia fue consultado sobre varios asuntos. Entre ellos, el de fijar la posición de España en el Congreso de Viena, respecto a las leyes y normas relativas a los tratados de comercio con las potencias extranjeras. En el informe que entregó al respecto parece emerger nuevamente el Valiente reformista de fi- 
nales del siglo XVIII, sobre todo al insistir en la necesidad de aprovechar el momento para hacer importantes reformas que condujeran al libre comercio con extranjeros y pusieran fin a lo que quedaba del monopolio americano. Era consciente de que se trataba de una solución impostergable para el mantenimiento del imperio, debido a la situación en la que se encontraban las colonias a causa de las revoluciones que habían estallado por doquier.

Por esas mismas fechas el rey lo designó embajador de Suecia. Sin embargo, Valiente declinó el nombramiento por su delicado estado de salud. También fue nombrado miembro de la Junta de Correos y Postas. En septiembre de 1817 el rey quiso reconocerle los servicios prestados en los dominios de América, por lo que le concedió la Gran Cruz de la Real Orden Americana de Isabel la Católica. En octubre del mismo año falleció en Santa Cruz de Mudela.

José Pablo Valiente fue un destacado funcionario ilustrado. La defensa a ultranza de la monarquía absoluta y el imperio de ultramar fueron mayores que sus deseos de introducir mejoras en profundidad para asegurar la pervivencia de la monarquía y conservar los dominios coloniales. 